\title{
Prática docente da disciplina de Administração em Enfermagem: facilidades e dificuldades
}

\section{Teaching practice of the discipline of Nursing Administration: facilities and difficulties}

\author{
Cristiano Caveião ${ }^{1}$ \\ Ivete Palmira Sanson Zagonel ${ }^{2}$ \\ Aida Maris Peres ${ }^{3}$ \\ Ana Paula Hey ${ }^{4}$ \\ Juliana Helena Montezeli ${ }^{5}$ \\ Angelita Visentin Correio ${ }^{6}$
}

\section{RESUMO}

Trata-se de uma pesquisa de campo exploratório-descritiva com abordagem qualitativa, que objetivou identificar as facilidades e dificuldades inerentes à prática docente da disciplina de administração em enfermagem em cursos de graduação. Participaram seis Instituições de Ensino Superior (IES) privadas e seis públicas do sul do Brasil, totalizando 25 docentes, sendo 10 de instituições privadas e 15 de instituições públicas. Para a coleta das informações foi utilizada entrevista gravada no período de julho a setembro de 2012. Para a análise das informações utilizou-se a Técnica de Análise de Conteúdo de Bardin. Após a análise emergiram duas Unidades de Contexto: Estratégias facilitadoras para o desempenho da docência de administração em enfermagem; Docência de administração em enfermagem: dificuldades na inter-relação entre docentes, estudantes, profissionais de serviço e cenários. Os docentes entrevistados relatam como estratégias facilitadoras a experiência profissional, a utilização de metodologias ativas, participação do enfermeiro no campo de prática/estágio, entre outros. E fatores dificultadores as oportunidades da vivência de determinados dimensões como liderança, gerência do serviço, participação em atividades que estão ligadas a hierarquias superiores, em que o estudante não pode participar, pois não existe a abertura de novos cenários.

Palavras-chave: Enfermagem; Educação em Enfermagem; Docentes de Enfermagem.

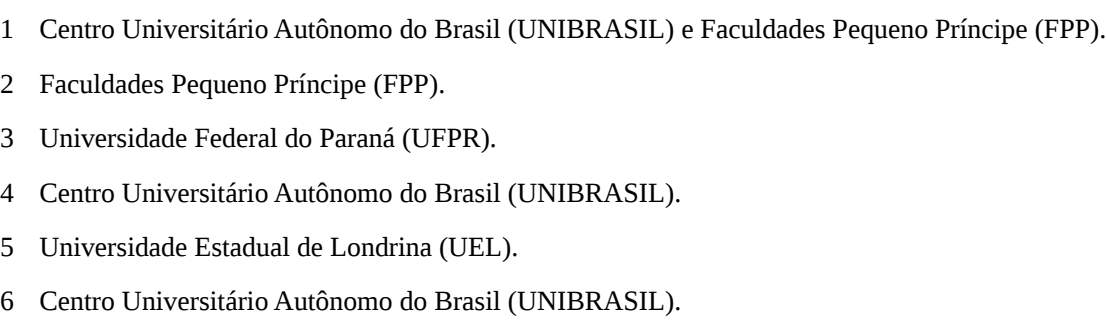


This is an exploratory-descriptive field with a qualitative approach, which aimed to identify the advantages and difficulties inherent in the discipline of nursing administration in undergraduate teaching practice. Participants were six Higher Education Institutions (HEIs) private and six public from southern Brazil, totaling 25 teachers, and 10 private institutions and 15 public institutions. To collect the information recorded in the period July-September 2012 interview was used. To analyze the information we used the technique of content analysis of Bardin. After analyzing two units of context emerged: Strategies to facilitate the performance of the teaching of nursing administration; Teaching of nursing administration: difficulties in inter-relationship between teachers, students, professionals and service scenarios. The interviewed teachers described as facilitating strategies work experience, the use of active methodologies, participation of nurses in the field of practice/training, among others. And complicating factors the opportunities of experiencing certain dimensions such as leadership, service management, participation in activities that are linked to higher hierarchies, in which the student cannot participate because there is no opening new scenarios.

Keywords: Nursing; Education in Nursgin; Faculty Nursing.

\section{INTRODUÇÃO}

As práticas administrativas permeiam a atuação do enfermeiro nos mais diferentes cenários em que este profissional exerce as suas atividades laborais, correspondendo a uma das dimensões do seu processo de trabalho. Assim, o ensino da administração em enfermagem favorece a formação do enfermeiro para alicerçar as suas práticas cuidativas e gerenciais no cotidiano profissional. As consonâncias e dissonâncias entre as demandas institucionais e as funções administrativas que de fato são de responsabilidade do enfermeiro, tornam o ensino da administração em enfermagem um desafio aos docentes.

O processo de aprendizado, que inclui o ensino e a aprendizagem de administração em enfermagem permite pensar em duas temáticas centrais: o ensino e os papéis dos atores envolvidos nesse processo. $\mathrm{O}$ ensino, na perspectiva da administração em enfermagem, tem o papel de contribuir para que haja uma transformação contínua no cenário de discentes e docentes, permitindo a aprendizagem, além de sua formação pessoal e profissional (PRADO et al, 2010).

No que se refere ao ensino de administração em enfermagem, reforça-se no Brasil os indicativos das Diretrizes Curriculares Nacionais para os Cursos de Graduação em Enfermagem (DCNGE), que estabelecem entre outros tópicos, os campos de estudo e demais experiências de ensino-aprendizagem que devem compor os currículos. Tal item busca incentivar uma sólida formação geral, necessária para que o discente possa superar os desafios condicionados ao seu exercício profissional, que estão em constante modificação; o que inclui a produção do conhecimento (BRASIL, 2001).

A busca do perfil profissional, alinhado às Diretrizes Curriculares Nacionais, durante a formação acadêmica, é permeada por situações que podem dificultar ou facilitar o processo de aprendizado de administração em enfermagem. Um tema relevante, nesse sentido, são as situações de aprendizagem vivenciadas na disciplina de administração em enfermagem, que possibilitam a união da teoria à prática, contribuindo para a inserção do discente na prática profissional; além de possibilitar contribuições para a melhoria da qualidade de vida da população envolvida e sociedade (CAVEIÃO et al, 2013; PRADO et al, 2010).

Porém, evidencia-se que é importante considerar alguns intervenientes nesse processo, como a participação dos enfermeiros do campo de estágio no processo de aprendizado (LIMA et al, 2014); a metodologia de ensino utilizada pelos docentes (VARGAS et al, 2012); os sentimentos vivenciados pelos discentes (SILVA et al, 2009); entre outros temas. 
Destarte, ao longo do percurso profissional dos autores como docentes de administração em enfermagem, percebeu-se, empiricamente, a existência de fatores que podem facilitar ou representar um obstáculo a tal prática, emergindo, assim, a necessidade de aprofundamento sobre o tema, guiada pela seguinte questão norteadora: Quais as facilidades e dificuldades inerentes à prática docente da disciplina de administração em enfermagem em cursos de graduação? Assim, o objetivo foi: identificar as facilidades e dificuldades inerentes à prática docente da disciplina de administração em enfermagem em cursos de graduação.

\section{MÉTODO}

Esta pesquisa de campo caracteriza-se como exploratório-descritiva com abordagem qualitativa. Foram convidadas seis Instituições de Ensino Superior (IES) privadas e seis públicas do sul do Brasil que possuem o curso de Graduação em Enfermagem reconhecido pelo Ministério de Educação e Cultura (MEC) para compor a amostra, todas aceitaram.

Após contato com os coordenadores de curso, os mesmos forneceram uma lista com e-mail e telefone de 40 docentes que ministravam a disciplina de Administração em Enfermagem. Destes, aceitaram participar 25 docentes, sendo 10 de instituições privadas e 15 de instituições públicas.

Foram utilizados como critérios de inclusão: ser docente da disciplina de administração em enfermagem ou com designação similar em seus cursos de graduação; pertencer a uma instituição de ensino superior privada ou pública reconhecida pelo MEC. Foram excluídos os docentes que não ministravam a disciplina de administração em enfermagem no momento da coleta de informações, docentes de curso não reconhecido pelo MEC, que não aceitaram participar do estudo e os que estavam em licença ou atestado médico no período de pesquisa.

O projeto de pesquisa foi aprovado pelo Comitê de Ética em Pesquisa com seres humanos (CEP) sob o registro $n^{\circ}$ 1067/12. Para preservar o anonimato dos participantes optou-se, por identificá-los com as codificações: Instituição Pública - Pub 1, Pub 2, Pub 3...; Instituição Privada - Priv 1, Priv 2, Priv 3... Todos assinaram o Termo de Consentimento Livre e Esclarecido (TCLE). Foram seguidas as recomendações da Resolução 466/2012 que regulamenta pesquisa envolvendo seres humanos (BRASIL, 2012).

Para a coleta das informações foi utilizada entrevista gravada no período de julho a setembro de 2012, com duração aproximada de 30 minutos, tendo como questão norteadora: quais as facilidades e dificuldades inerentes a sua prática docente de administração em enfermagem?

Para a análise das informações utilizou-se a Técnica de Análise de Conteúdo (BARDIN, 2011) que compreende três momentos: pré análise, exploração do material e tratamento dos resultados (inferência e interpretação). As etapas adotadas para construção consistente das categorias foram: $1^{\circ}$ - Após a transcrição na íntegra das entrevistas gravadas, realizou-se uma leitura dos textos a partir de uma atenção flutuante; $2^{\circ}$ - Por meio de nova re-leitura, foram grifadas palavras e frases dos textos originais, identificando-se convergências e divergências em cada entrevista; $3^{\circ}$ - Após serem identificadas as convergências e divergências, palavras e frases grifadas foram recortadas dos textos originais; $4^{\circ}$ - Após o recorte das palavras e frases, buscou-se identificar convergências e divergências em cada entrevista e entre as entrevistas, para a elaboração das categorias; $5^{\circ}$ - Após a construção das categorias, procedeu-se a discussão dos dados.

\section{RESULTADOS E DISCUSSÃO}

A partir da análise dos dados acerca das facilidades e dificuldades inerentes prática docente da disciplina de administração em enfermagem em instituições de ensino superior, foi possível destacar as Unidades de Contexto e Unidades de Significação que indicam as facilidades e dificuldades inerentes à prática docente de 
administração em enfermagem apreendidas dos depoimentos. Os resultados são apresentados em duas tabelas que mostraram as facilidades (Tabela 1) e as dificuldades (Tabela 2).

\section{Tabela 1 - Representação das estratégias facilitadoras para o desempenho da docência de administração em enfermagem apreendidas pela análise.}

\begin{tabular}{|c|c|c|}
\hline $\begin{array}{l}\text { UNIDADES DE } \\
\text { CONTEXTO }\end{array}$ & $\begin{array}{l}\text { UNIDADES DE } \\
\text { SIGNIFICAÇÃO }\end{array}$ & DEPOIMENTOS \\
\hline \multirow[t]{3}{*}{$\begin{array}{l}\text { Estratégias } \\
\text { facilitadoras para } \\
\text { o desempenho } \\
\text { da docência de } \\
\text { administração em } \\
\text { enfermagem }\end{array}$} & $\begin{array}{l}\text { Experiência } \\
\text { profissional do } \\
\text { docente }\end{array}$ & $\begin{array}{l}\text { O professor de administração deve possuir experiência nessa área, acho } \\
\text { que ele tem que ter vivido, ter sido um diretor, ele tem que ter sido um } \\
\text { enfermeiro supervisor de unidade (Pub 15). } \\
\text { É muito complexo ensinar aquilo do que não se conhece ou que não se } \\
\text { vivenciou. A partir do momento que você tem uma vivência enquanto } \\
\text { gerente de um serviço, de uma unidade, eu acredito que isso facilite muito, } \\
\text { na hora de passar os conteúdos referentes a essa disciplina (Pub 2). } \\
\text { Eu vejo que a experiência profissional contribui, pois o docente tem a } \\
\text { vivência prévia sobre a administração auxilia no ensinar (Priv 6). }\end{array}$ \\
\hline & $\begin{array}{l}\text { Uso de metodologias } \\
\text { ativas }\end{array}$ & $\begin{array}{l}\text { É muito mais você passar um conteúdo através de problematização, de } \\
\text { metodologias ativas, mesmo que seja através de várias [...]. Que você } \\
\text { utilize métodos ativos de ensino. Então, a metodologia ativa tira o aluno } \\
\text { dessa inércia, quer dizer, aquele que deseja, também não faz mágica tá } \\
\text { (Pub 15). } \\
\text { Nós aqui utilizamos metodologias ativas para o ensino (Priv 1). }\end{array}$ \\
\hline & $\begin{array}{l}\text { O tipo de campo } \\
\text { de estágio e a } \\
\text { participação do } \\
\text { enfermeiro }\end{array}$ & $\begin{array}{l}\text { A participação dos enfermeiros do serviço ou dos campos nas discussões } \\
\text { pedagógicas, na construção do nosso currículo, na construção do módulo. } \\
\text { Então, o enfermeiro do serviço se sentindo parceiro do processo de } \\
\text { formação do aluno (Pub 15). } \\
\text { A articulação que se constrói com os enfermeiros do campo, é uma } \\
\text { facilidade. Como nós não estamos lá o turno inteiro, então a gente sabe } \\
\text { que pode contar com eles (Pub 9). } \\
\text { O enfermeiro e o campo de estágio contam muito, pois quando ele } \\
\text { oportuniza o aprendizado ao aluno, nos podemos ficar tranquilos (Priv 1) }\end{array}$ \\
\hline
\end{tabular}

Fonte: Dados da pesquisa

As Estratégias facilitadoras para o desempenho da docência de administração em enfermagem consideram a experiência profissional do docente ao desenvolver a disciplina, pois pauta-se, sobretudo nas situações já vivenciadas dentro da área de gestão e assistência de enfermagem durante a prática profissional. O conhecimento adquirido anteriormente auxilia para ministrar a disciplina, pois facilita o processo de ensino e aprendizagem.

Os docentes que possuem experiência na assistência de enfermagem apresentam melhor desempenho no exercício da profissão (SILVA et al, 2009). O estudo sobre a compreensão da ação docente, sob o ponto de vista do professor e do aluno, concluiu que o docente deve envolver-se com os seus alunos, conhecer o conteúdo a ser lecionado e ter experiência clínica (PRADO e LEITE, 2010). Os docentes dessa pesquisa relatam que a utilização das metodologias ativas contribui para a melhor participação dos alunos em sala, pois deixa de ser o sujeito passivo e passa a ser o sujeito ativo, além disso, destacam a possibilidade de trabalhar em pequenos grupos.

Nesse sentido, o uso de metodologias ativas em cursos de graduação em enfermagem gera diversos desafios, desde os estruturais, como: organização acadêmica e administrativa das instituições e cursos; até os de concepções pedagógicas: crenças, valores e modos de fazer dos professores e alunos. As metodologias ativas requerem do docente de administração em enfermagem flexibilidade e capacidade de articulação, pois elas são ferramentas para alcançar o sujeito ativo, crítico, capaz de transformar-se e ser transformador de seu contexto. Assim, as técnicas de ensino utilizadas, devem propiciar que se trabalhe a representação do conjunto das questões, estimulando a comunicação, o trabalho em equipe, os contratos que se fazem, bem como as formas de con- 
vivência, permitindo a manifestação e levando em conta o tempo de aprendizagem de cada aluno (FERNANDES et al, 2010; VARGAS et al, 2012; SOBRAL e CAMPOS, 2012; TRINDADE et al, 2014).

As metodologias ativas para o processo de ensino e aprendizagem, não garantem por si a ruptura de velhos paradigmas, se faz necessário a transformação de concepções inerentes ao processo ensino-aprendizagem para que possam ser ressignificadas em uma perspectiva emancipadora da educação (SOBRAL e CAMPOS, 2012).

Os depoimentos salientam que uma das estratégias que facilitam o desempenho do docente em administração em enfermagem é a participação da IES, e quando esta está vinculada ao Hospital Universitário, pois o enfermeiro possui maior proximidade com as questões relacionadas ao ensino e as oportunidades que os alunos vivenciam para a prática profissional.

A participação do enfermeiro de campo respalda o trabalho docente. Além disso, torna o trabalho do docente facilitado, pois ele não está presente em tempo integral ao lado do aluno e possui o enfermeiro para orientá-lo diante das dificuldades encontradas no momento. Relatam também ser importante a participação do enfermeiro, no que se refere às questões pedagógicas, pois auxilia na construção do processo de formação.

As DCNCGE asseguram que os enfermeiros que atuam nas instituições de saúde onde se desenvolve o Estágio Curricular Supervisionado, devem participar no processo de ensino e aprendizagem do aluno (BRASIL, 2001).

O enfermeiro atuante na prática tem papel fundamental no processo de aprendizagem do aluno que desenvolve o estágio curricular em sua unidade de trabalho, pois será uma referência importante de trabalho, o facilitador e o integrador do aluno ao serviço e a equipe de saúde, sendo necessário que este profissional esteja seguro para transmitir a sua experiência (SILVA et al, 2009, CAVEIÃO et al, 2013; LIMA et al, 2014).

Em relação às facilidades da prática do docente de administração em enfermagem, os discursos apresentam a necessidade da experiência profissional na área da gestão, o que representa uma facilidade do processo de ensino e aprendizagem. Já no que tange o uso de metodologias ativas consideram que estas técnicas facilitam, contribuem para a melhor participação dos alunos em sala, pois passam a ser os sujeitos ativos e participam da formação.

Diante da formação do aluno de administração em enfermagem, a participação do enfermeiro do campo respalda o trabalho docente, pois facilita, visto que ele está presente o tempo todo com o aluno podendo sanar as suas dúvidas, e é de suma importância a sua participação no processo de aprendizado. 


\section{Quadro 2 - Representação das dificuldades na inter-relação entre docentes, estudantes, profissionais} de serviço e cenários na docência de administração em enfermagem apreendidas pela análise.

$\begin{array}{ll}\begin{array}{l}\text { UNIDADES DE } \\ \text { CONTEXTO }\end{array} & \text { UNIDADES DE } \\ \text { SIGNIFFICAÇÃO }\end{array}$

A participação do enfermeiro nos cenários de prática ou estágio

\section{DEPOIMENTOS}

[...] acho que os alunos deveriam ter uma liberdade maior, nós

não permitimos isso, temos muito medo daquilo que ele faça, e consequentemente isso faz com que ele não pense criticamente, se desvencilhe de algumas coisas (Priv 3).

Eles [os estudantes] ficam sozinhos pela primeira vez no estágio de Gestão e Gerenciamento. Referem uma dificuldade inicial, mas, depois se sentem bem com a autonomia que eles conquistam, em poder pensar e tomar algumas decisões dentro daquele estágio (Pub 9).

Os enfermeiros das unidades têm uma certa resistência ainda, a essa questão de ver o aluno de administração, como um parceiro que agrega e que vai ajudar a melhorar o serviço (Pub 14).

$\mathrm{O}$ rodízio de enfermeiros na mesma unidade. Passa um enfermeiro, outro, aí você percebe que isso tem uma dificuldade no aprendizado do aluno (Pub 12).

Observamos pouco envolvimento dos enfermeiros de campo para acolher esse aluno e mostrar como a administração está envolvida em seu cotidiano (Priv 7).

Perfil do estudante como fundamental no processo de aprendizado

Acredito que é complexo desenvolver uma competência gerencial, em um indivíduo que vive em um ambiente de opressão diária, com falta de dinheiro, sono prejudicado e tripla jornada (Priv 8).

Outra dificuldade é a pouca leitura que os alunos fazem sobre os conteúdos e em alguns casos, dificuldades de entendimento mesmo do conteúdo (Priv 7).

Nós temos alunos que não cresceram ainda, e provavelmente essa lacuna ficou na formação. Então a gente tem sim alunos que não conseguiram se destacar e, mesmo na assistência, a gente percebe a dificuldade que ele tem de administrar o cuidado daquele paciente, daquela unidade que ele se encontra (Pub 8).

Uma grande dificuldade é essa concepção de que a administração tem que ser ensinada, ou que ela só faz parte do último ano da graduação, e não desde o início; e a dicotomia que há entre o administrar e o cuidar, eu sinto que é a grande dificuldade. Outro ponto é a carga horária, embora foi reformulada a partir das novas diretrizes, ela ainda é pequena, eu acredito que 162 horas são poucas ainda pra gente trabalhar, não digo tudo mas, o mínimo pra que esse aluno tenha competências (Pub 2).

O curto espaço de tempo que a disciplina é ministrada (em bloco). Não tem um espaço para o aluno refletir em cima daquele conteúdo. Então, acho que seria importante diluir mais essa disciplina ao longo do semestre (Pub 9).

A carga horária sempre a gente percebe a necessidade de que poderia ser maior, pra proporcionar mais discussões, proporcionar que o aluno entre em contato com os mais diversificados conteúdos e cenários de prática (Priv 1).

Instituição de ensino
Investimento em literatura pela instituição, a biblioteca esta defasada (Priv 7).

A instituição coloca 6 campos para a visita diária desse aluno e não paga auxilio de deslocamento e nem hora atividade (Priv 1).

A dificuldade é a organização do processo de trabalho, no que se refere à instituição de ensino enquanto empresa. Muitas vezes, tem-se que supervisionar uma quantidade grande de alunos em diferentes campos de estágio, sem ajuda de custo, com hora aula reduzida para acompanhar o estágio, não recebendo hora atividade (Priv 8). 
A segunda Unidade de Contexto, Docência de administração em enfermagem: dificuldades na inter-relação entre docentes, estudantes, profissionais de serviço e cenários é possível observar pelos depoimentos, que o estudante de enfermagem está acostumado com a presença do docente ao seu lado para a realização da prática, ele fica dependente do acompanhamento docente, e apresenta dificuldades de exercitar a autonomia, quando inicia o estágio de último ano, com supervisão indireta. Ao manter-se no campo sem a supervisão direta do docente, a liberdade e autonomia são potencializadas, para gerenciar as suas próprias ações.

Os cursos de graduação em enfermagem devem incluir o Estágio Curricular Supervisionado nos dois últimos semestres, conforme preconizado pelas DCNCGE devido a necessidade do domínio de conteúdos teóricos e práticos, pois neste momento ele terá em seu processo de supervisão o acompanhamento do docente e do enfermeiro do serviço (BRASIL, 2001).

A partir deste momento, o estudante passa a se inserir na realidade, passando a vivenciar a atuação profissional do enfermeiro em seu contexto histórico, político, social, cultural e financeiro com a tutoria do docente e a supervisão direta do enfermeiro assistente/supervisor de campo. Essa vivência oportuniza ao estudante, a construção de conhecimentos, habilidades e valores em articulação com a equipe de enfermagem e de saúde (PRADO et al, 2010; FERNANDES et al, 2010; LIMA et al, 2014).

O desempenho das atividades de estágio sem a supervisão direta de docentes, de acordo com os depoimentos, suscita nos estudantes, sentimentos de medo, insegurança, dificuldades. Porém, com o passar do tempo, se adaptam e conquistam autonomia na tomada de decisão, sem a presença constante do docente de administração em enfermagem.

O período de estágio pode ser considerado um momento crítico para os acadêmicos, visto que é uma etapa de transformações intensas no modo de pensar-agir. Um mundo novo está à frente de jovens que se deparam com sentimentos diferenciados e, muitas vezes, nunca experimentados, como medo, ansiedade, piedade, necessidade de paciência e empatia. Essas transformações fazem parte do processo educativo e da prática pedagógica moderna em que o aprender a ser, aprender a fazer, aprender a conhecer e aprender a conviver constituem-se base para a formação de profissionais competentes e decisivos no mercado de trabalho (SILVA et al, 2009; LIMA et al, 2014, RODRIGUES et al, 2014).

Os docentes estabelecem dificuldades enfrentadas em relação aos cenários de prática/estágio, entre as quais citam a pouca colaboração do enfermeiro que está no campo realizando o acompanhamento do aluno, pois ele não percebe-o como um colaborador dentro de suas ações ou dimensiona-o como um colega do seu plantão.

O estágio curricular deve ser planejado e preparado de forma articulada e interdisciplinar, além da necessidade de preparar a instituição, campo de estágio e principalmente, preparar o enfermeiro assistencial que irá participar efetivamente do processo de ensino-aprendizagem do estudante de graduação em enfermagem (SILVA et al, 2009).

Os docentes referem que os enfermeiros não oportunizam aos alunos a vivência de determinados dimensões como liderança, gerência do serviço, participação em atividades que estão ligadas a hierarquias superiores, em que ele não pode participar das outras instâncias do poder, pois não existe a abertura de novos cenários.

Ressaltam que a presença do estudante no campo não pode ser confundida com o papel do enfermeiro gerente, pois ainda está em processo de formação. Estas colocações conduzem a uma reflexão sobre o processo de liderança, o qual está determinado pela sua abrangência de significados e não restrito ao contexto gerencial, no caso do enfermeiro. 
O estágio curricular deve oportunizar ao aluno uma experiência “pré-profissional”, onde ele possa vivenciar o desempenho das atividades do profissional enfermeiro, com a orientação do docente e acompanhamento do enfermeiro assistencial na realidade do campo (SILVA et al, 2009; PRADO et al, 2010). Com esta oportunidade ele pode colocar em ação como se fosse seu primeiro emprego.

Neste momento, a ele deve ser oferecida oportunidade de aplicação e aprimoramento dos conhecimentos teóricos e práticos adquiridos durante a vivência acadêmica para a profissional. Portanto, é de vital importância o local onde o estagiário está atuando e os profissionais envolvidos no processo de aprendizado, e principalmente a influência do enfermeiro assistencial em relação ao desenvolvimento do estágio (SILVA et al, 2009).

Os docentes referem ainda, que o enfermeiro do campo utiliza este aluno como um auxiliar para compor a equipe de trabalho, porém este não é o objetivo do aluno e cabe ao docente intermediar a situação e envolve-lo ao trabalho de acordo com o perfil profissional preconizado pela instituição.

Em virtude da longa duração da disciplina e contato próximo com a equipe de enfermagem e equipe multiprofissional, é importante que o aluno tenha uma adaptação favorável, caso não ocorra poderá refletir de forma negativa no desenvolvimento técnico e pessoal deste aluno. Desta forma, requer tempo, paciência e certa generosidade por parte da equipe hospitalar para remanejar funções em direção aos alunos, oportunizando a prática tão esperada por estes (Silva et al, 2009).

Outro ponto observado nos discursos é a alta rotatividade dos enfermeiros no campo de estágio, o que gera dificuldades no processo de aprendizado.

A preocupação do docente em relação ao desenvolvimento do aluno durante o processo de aprendizagem auxilia a perceber e conhecer o perfil do estudante. Há relatos sobre o desinteresse, descaso com a disciplina, por não considerarem importante, mas muitas vezes o desinteresse está relacionado a uma jornada de trabalho excessiva, falta de leituras e consequente entendimento dos conteúdos.

Estudos têm apontado a irregularidade dos padrões de sono de estudantes, que necessitam atrasar o início e final do sono nos dias de semana, devido às atividades escolares (PEREIRA et al, 2011) e as consequências dessas alterações.

Há uma lacuna no conhecimento acerca do sono dos estudantes diurnos que são trabalhadores noturnos, como os da enfermagem, que possuem jornada de 12 horas de trabalho por 36 horas de descanso, e frequentam a faculdade imediatamente após o trabalho, sem a possibilidade de terem um período de descanso ou cochilo antes do início da aula (PEREIRA et al, 2011).

A organização curricular é relatada pelos entrevistados como uma das dificuldades no desenvolvimento da disciplina de administração em enfermagem, pela oferta da disciplina ocorrer no último ano do curso e na maioria das vezes, concentrada em um bloco. Esses docentes expressaram que a carga horária atual da disciplina é insuficiente para promover e proporcionar melhores discussões sobre determinados assuntos.

Em pesquisa obteve-se a deficiência na distribuição e integração dos conteúdos relacionados à administração em enfermagem, onde na matriz curricular, a carga horária destinada à disciplina concentrava-se no último semestre do curso. A carga horária teórico-prática da disciplina de administração poderia ser maior, para enfatizar o desenvolvimento de competências administrativas (MEIRA e KURCGANT, 2009).

Os docentes entrevistados relatam que dependendo da instituição de ensino a que pertencem, não há investimento em literatura, não é fornecido auxílio para a realização da supervisão em diversos campos, além do baixo salário. As dificuldades encontradas pelos professores em fase inicial compreendem as de natureza administrativa, pedagógica, envolvimento com os discentes, entre outras. 
Em estudo com professores, estes relataram que a forma de contratação (sem vinculo empregatício), é um dos fatores dificultantes em sua jornada de trabalho (ALVES e PINTO, 2011; CARNEIRO, 2013). Outras pesquisas salientaram que a remuneração do docente, demanda de trabalho, falta de incentivo, dificuldade em participar de congressos são fatores que interferem no desenvolvimento do trabalho (RABELO, 2010; PRADO et al, 2010; SOARES et al, 2011; ALVES e PINTO, 2011; CARNEIRO, 2013).

Há relatos sobre a falta de publicações relacionadas à administração em enfermagem e investimento das instituições de ensino, na formação do docente na área de gestão.

\section{CONSIDERAÇÕES FINAIS}

Os docentes entrevistados relataram a experiência profissional, a utilização de metodologias ativas para o processo de aprendizado da disciplina e a participação do enfermeiro no campo de prática/estágio. As situações já vivenciadas pelos docentes, a experiência na área assistencial e de gestão em enfermagem possibilitam maior compreensão do aluno na disciplina. A participação do enfermeiro nos cenários de prática e a instituição de ensino superior estar vinculada a hospital universitário foram indicadas pelos docentes como propiciadoras de maior proximidade com as questões relacionadas ao ensino e as oportunidades que os alunos vivenciam na prática em saúde. Relatam ainda, que essa articulação torna o trabalho do docente facilitado, pois ele não está presente em tempo integral ao lado do aluno. A participação do enfermeiro de campo é estratégica e fundamental, para orientar os acadêmicos diante das dificuldades encontradas.

Além dos aspectos positivos da participação do enfermeiro de campo no processo de aprendizado, os docentes deste estudo expressaram também uma dificuldade, pois em algumas situações o enfermeiro não visualiza o estudante da disciplina de administração em enfermagem, como um colaborador dentro de suas ações ou acaba dimensionando-o como um colega do seu plantão. Também destaca-se a dificuldade das oportunidades da vivência de determinados dimensões como liderança, gerência do serviço, participação em atividades que estão ligadas a hierarquias superiores, em que o estudante não pode participar, pois não existe a abertura de novos cenários.

Frente às dificuldades apresentadas nos discursos dos docentes destaca-se a dificuldade do aluno conduzir-se sozinho na realização da prática, gerenciando as suas próprias ações. Sugere-se que a inserção dos conteúdos de administração em enfermagem ocorra desde o início da formação e que o aluno possa se inserir dentro da realidade, passando a vivenciar a atuação profissional do enfermeiro e que a carga horária atual possa ser revista, pois relatam que é insuficiente para promover e proporcionar melhores discussões sobre determinados temas.

Nos cenários de prática destacam-se que, o enfermeiro não acompanha o estudante e o reconhece como colega de trabalho, não oportunizando a vivência de determinadas dimensões como liderança, gerência do serviço, participação em atividades que estão ligadas a hierarquias superiores.

Em relação ao perfil do aluno, pode-se observar o desinteresse, descaso com a disciplina por não considerarem importante. Em muitas situações esse desinteresse está relacionado a jornada de trabalho excessiva, falta de leitura e entendimento dos conteúdos por parte dos estudantes.

Em relação às instituições de ensino obteve-se que os docentes entrevistados relatam que as instituições a que pertencem não investem em bibliografia, não fornecem auxílio para a realização da supervisão em diversos campos, hora aula reduzida para a supervisão do estágio e baixa remuneração. Surgem alguns desafios a serem superados, pois alguns docentes não possuem formação na área de gestão e atuam na disciplina de administração em enfermagem devido a questões institucionais. Novos estudos necessitam ser realizados para que a produção do conhecimento nessa área possa alicerçar estratégias facilitadoras e indicar possíveis entraves no desempenho docente de administração em enfermagem. 


\section{REFERÊNCIAS}

ALVES, T.; PINTO, J. M. R. Payment and characteristics of the teaching work in Brazil: a contribution of data from school census and PNAD. Cadernos de Pesquisa. Rio de Janeiro, 2011, v. 41, n.143, p. 606-639. ISSN 0100-1574.

BARDIN, L. Análise de conteúdo. São Paulo: Edições 70; 2011.

BRASIL. Conselho Nacional de Educação. Câmara de Educação Superior. Resolução CNE/CES 3/2001. Institui Diretrizes Curriculares Nacionais do Curso de Graduação em Enfermagem. Diário Oficial da União. Brasília. 2001.

BRASIL. Ministério da Saúde. Resolução N 466, de 12 de Dezembro de 2012. Trata de pesquisas e testes em seres humanos. 2012.

CARNEIRO, P. O. Ensino superior no brasil e o trabalho docente. Revista Encontro de Pesquisa em Educação. Uberaba, 2013, v. 1, n.1, p. 154-102. ISSN 1809-7901.

CAVEIÃO, C.; et al. A produção do conhecimento sobre competências gerenciais de enfermagem: revisão integrativa. Revista de Enfermagem UFPE. Recife, 2013, v 7 (edição especial), p. 910-8. ISSN 1981-8963.

FERNANDES, M. C. G. O.; et al. Representação da participação do enfermeiro no processo educativo e nas relações humanas do trabalho. RAS. São Paulo, 2010, v. 12, n. 46, p. 31-40.

LIMA, T. C.; et al. Estágio curricular supervisionado: análise da experiência discente. Revista Brasileira de Enfermagem. Brasília, 2014, v. 67, n. 1 p. 133-140. ISSN 0034-7167.

MEIRA M. D. D.; KURCGANT, P. O ensino de administração na graduação: percepção de enfermeiros egressos. Revista Texto \& Contexto Enfermagem. Florianópolis, 2009, v. 18, n. 4, p. 670-9. ISSN 0104-0707.

PEREIRA; E. F.; et al. Sono, trabalho e estudo: duração do sono em estudantes trabalhadores e não trabalhadores. Cadernos de Saúde Pública. São Paulo, 2011, v. 27, n. 5, p. 975-84. ISSN 0102-311X.

PRADO, C. LEITE, M. M. J. Compreendendo as intenções das ações de um corpo docente multiprofissional em um curso de graduação em enfermagem. Revista Brasileira de Enfermagem. Brasília, 2010, v. 63, n. 4, p. 548-54. ISSN 0034-7167.

PRADO, C.; et al. Avaliação no estágio curricular de administração em enfermagem: perspectiva dialética. Revista Brasileira de Enfermagem. Brasília, 2010, v. 63, n. 3, p. 487-490. ISSN 0034-7167.

RABELO, A. O. A remuneração do professor é baixa ou alta? Uma contraposição de diferentes referenciais. Educação em Revista. Curitiba, 2010, v. 26, n. 1, p. 57-88. ISSN 0104-4060

RODRIGUES, L. M. S.; et al. Interaction, education and helath services for the development of the supervised internship in nursing in primary health care. Journal of Research Fundamental Care Online. Rio de Janeiro, 2014, v. 6, n. 1, p. 357-363. ISSN 2175-5361

SILVA, R. M.; et al. Ensino de enfermagem: reflexões sobre o estágio curricular supervisionado. Revista PRAXIS. Rio de Janeiro, 2009, v. 1, n. 1, p. 37-41. ISSN 2176-9230.

SOARES, R. J. O.; et al. Fatores facilitadores e impeditivos no cuidar de si para Docentes de enfermagem. Revista Texto \& Contexto Enfermagem. Florianópolis, 2011, v. 20, n. 4, p. 758-65. ISSN 0104-0707 
SOBRAL, F. R.; CAMPOS, C. J. G. Utilização de metodologia ativa no ensino e assistência de enfermagem na produção nacional: revisão integrativa. Revista Escola de Enfermagem USP. São Paulo, 2012, v. 46, n. 1, p. 208-18. ISSN 1980-220X.

TRINDADE, C. S.; et al. Learning objects: an integrative review in healthcare. Health Informatics Journal. Canada, 2014, v. 6, n. 1, p. 20-9 ISSN 1460-4582

VARGAS, R. O. L. C. O.; et al. The problemation method applied to the subject nursing administration. Investigación y Educación en Enfermería. Antioquia, 2012, v. 30, n. 2, p. 269-276. ISSN 0120-5307. 